\title{
Effects of the Language of Instruction on Learning in Secondary Education and Its Implications in Workforce Preparation: A Case of Dodoma, Tanzania
}

\author{
Lazaro Alman Kisumbe \\ Local Government Training Institute, Dodoma, Tanzania, \\ Department of Human Resource Management \\ E-mail: lkisumbe04@yahoo.com \\ Yusuph Lameck Mashala \\ Local Government Training Institute, Dodoma, Tanzania \\ Department of Local Government Administration and Management \\ E-mail: m_lameck@yahoo.com
}

Received: Jul. 20, 2020 Accepted: Aug. 13, 2020 Online published: Sep. 10, 2020

doi:10.5296/jpag.v10i3.17370 ＵRL: https://doi.org/10.5296/jpag.v10i3.17370

\begin{abstract}
This paper intended to examine the effects of the language of instruction on Learning in secondary education in Dodoma region, and its implications in the preparation of the country's workforce. A total of 288 form one students at Ipala and Hombolo secondary schools were purposely and conveniently selected into the study. Standard seven past papers including geography, history, and civics were used as model papers to test the effects of the Language of instruction in students' learning. The same examination was conducted to the same group in each school administered in English and later in the Kiswahili language. A Paired sample t-test (dependent t-test) for paired samples was used to compare means of correlated samples and to test the null hypothesis that "there is no significant difference between the sample means". Each sample from the population was measured twice. It was revealed that the students' scores in the examination differed due to the difference in the language of instructions. The scores in grade-wise revealed the poor performance of the examination in English when compared with the same examination in the Kiswahili language. We found that the use of the English language inhibits the understanding of the subject and
\end{abstract}


limits the rooms for active involvement in training and learning, which is a prerequisite for understanding. Thus, it affects the efforts to prepare the future workforce to propel the realization of education policy and its contribution to the Tanzania National Development Vision 2025. We recommend designing operational strategies for implementation of the National Education and Training Policy, 2014 that directs the use of Kiswahili as the instructional language in all levels of education in the country.

Keywords: language of instruction, learning, secondary education, workforce preparation, Tanzania

\section{Introduction}

The relationship between language and academic performance has triggered the attention of different scholars (Prinsloo et al., 2018; Rudd and Honkiss, 2020; Kombaand Bosco, 2015). Generally, it is construed that language is a vehicle to transfer and acquire knowledge and skills. The proficiency in the language of training and learning by both teachers and students enhances the quality of education. The quality of education is enhanced by making training and learning interactive and hence learning taking place. In the same perspective, Rudd and Honkiss (2020) documented that the higher the students' proficiency skills in English, the higher the GPA of the respective students in Bangkok private universities. Similar results were reported by Rafiuand Nwalo (2016) students' performance in the cataloguing and classification courses in Nigeria. Also, Prinsloo et al. (2018) reported that the frequency with which the learners used the school language at home was strongly associated with the Science achievement results of Grade Nine learners in South Africa. Kombaand Bosco (2015) documented that students whose medium of instruction at primary school level was English performed better in form one annual examinations and form two national examinations in Mbeya region than their counterparts who had used Kiswahili as a medium of instruction in primary schools. Further, Kinyaduka, and Kiwara (2013) in Morogoro Region, Tanzania found that $69.5 \%$ of the students could not understand when taught in the English language. The findings also reported that $78.9 \%$ of the teachers perceive the use of English in secondary schools in the region as an inhibiting factor for quality education. Similarly, McCoy (2017) established that teaching in the English language detrimentally affected Kenya's upper primary school students' learning due to the teachers' limited language proficiency. The difficulties encountered by teachers to explain scientific concepts contributed to the results. Marie (2013) examined the strategies used by university students in Rwanda to successfully deal with complex academic material in the English language. It was established that students use different languages at their disposal to negotiate to mean and construct knowledge, peer support systems, extensive reading, lecture attendance, completing assigned work, and memorization. The study recommended examining the strategies used by teachers to facilitate learning where English is used as a medium of instruction.

Kirui et al. (2017) found that teachers were of the views that inadequate competence in English as a medium of instruction contributed to the poor academic performance of the 26 community secondary schools in Arusha region. The students were unable to comprehend the knowledge and properly answer the questions. Thus, it is recommended for the improvement 
of language proficiency among teachers to improve students' academic performance. Similarly, Brock-Utne (2007) using a different approach of the investigation came to almost resembling results. The study made comparisons between the results from the control and experimental groups taught the same subject by the same teacher; one class taught in English Language and another in Kiswahili on the same topic, great discrepancies were noted. Thus, it was concluded that due to poor mastery of the English language by most of the teachers in Tanzania, the use of Kiswahili in secondary school would help to create a labour force with critical abilities and creative qualifications.

In 2014, Tanzania established the National education policy, which generally intends to guide the provision of quality education and skills to the citizens (URT, 2014). The policy advocates the use of Kiswahili as an instructional language in all levels of education in the country. The policy was meant to have an adequate prerequisite workforce to drive the realization of the target set therein the National Development Vision 2025. The vision aspires to have a well educated and learning society ingrained with a development mindset and capable of driving a competitive economy (URTm2002). The vision 2025 was meant to facilitate the country to move from developing to the emerging economy by 2025. In July 2020, the World Bank declared Tanzania to have successfully reached the middle-income economy World Bank (2020). The effective implementation of the education policy would stir up the workforce preparation with prerequisite skills to enhance the optimum realization of the Tanzania Development Vision 2025. It would also sustain the realized achievements and facilitate the movements into further stages of the country's development. This could be possible by enhancing trainees to effectively comprehend knowledge and skills facilitated in the language of the conversant and fluency. However, to date English remains the main instructional language in training and learning at secondary and tertiary education, the study focused to examine the effects of using the language in the academic performance and hence its implications in the preparation of the national workforce.

\section{Theoretical Reviews}

Training and learning is a process whose understanding is underpinned by several theories including behaviorism, cognitive, and constructivism. The theories provide insights on what makes training and learning take place (MacKenney, 2008 \& Fulton and Pritchard, 2009). Each of these theories has different underlying principles upon which effective training and learning are discerned to be made possible. However, in this study, behaviorisms and constructivism theories were employed to guide the understanding of the training and learning in situations where seven years of study students use Kiswahili and suddenly shift to English as a medium of instruction starting from primary to Higher Learning Institutions.

The behaviorism theory focuses on the stimulus and response (S-R) relationship. It postulates that response $(\mathrm{R})$ is a result of the applied stimuli (S). This was common when training and learning were focused on remembering the knowledge such as read, write, and doing some calculations (Edgar, 2012). It is perceived as the basis of the traditional teaching and learning in which drill, practice, and repetition are used for the purpose. The goals of reading are the mastery of isolated facts and skills (Taylor and MacKenney, 2008 \& Fulton and Pritchard, 
2009). The important variables of the theory for this study include stimulus triggered by the teacher in the course of training and response as a reaction of the student in the learning process. Nevertheless, the theory assumes that the relation between the teacher and the student is that of a pumping (teacher) and receiving (students). This makes the theory inadequate to uncover the training and learning perspectives in which knowledge is acquired through effective participation between the two (Edgar, 2012). This triggered the researchers to employ constructivism theory in trying to understand the effects of language in students' learning and its impacts in the preparation of the workforce in the country.

The constructivism theory was introduced to ameliorate the challenges, which positioned the teacher with the role of giving and the student at the receiving end. It is a student-centered active involvement; inquiry and discovery training and learning approach (Sjøberg, 2010). The approach makes meaning and knowledge socially constructed during the training and learning as a result of integrating the learners' life experiences in the learning process (Sjøberg, 2010 \& Suhendi, and Purwarno, 2018). Thus, it makes it possible to build knowledge based on the former accumulated information (schema) and (Pritchard, 2009). Likewise, such a type of training and learning facilitates learning context-specific knowledge. However, it remains unfolded on the possibility of active participation of teachers and students in the learning in the midst of language barriers. The use of Kiswahili in standard one to seven coupled with the language being national one and abruptly switching to English language at secondary school and tertiary education poses difficulties in mastering the language. It, therefore, brings shock to students and affect their academic performance in turn.

\section{Methodology}

The sample was drawn from Hombolo and Ipala secondary schools in Dodoma region, Tanzania. A total of 288 respondents were included in the study comprising of 100 respondents from Hombolo and 88 respondents from Ipala secondary school. The form one students in these schools were purposively and conveniently selected for the study. The standard seven social studies (geography, history, and civics) previous examination questions were used to test students' academic performance when administered in English and Kiswahili for the same respondents. This was purposely done knowing that form one education is in most cases build on the standard seven educations, thus, there is some continuation of the same and students can easily recall the previous knowledge. The quantitative analysis with the paired sample t-test also known as dependent t-test for paired samples was used to compare means of correlated samples. Each sample from the population was measured twice (examination in Kiswahili and English language). The paired sample t-test was used to test the null hypothesis that there is no significant difference between the sample means (i.e. the sample means are equal) against the alternative hypothesis that the sample means are not equal. That is

$$
\begin{aligned}
& \mathrm{H}_{0}: \overline{\mathrm{d}}=0 \\
& \mathrm{H}_{\mathrm{a}} \overline{\mathrm{d}}>0
\end{aligned}
$$




$$
\mathrm{H}_{\mathrm{a}} \overline{\mathrm{d}}<0
$$

Where ${ }^{-}$by the difference between the samples is means i.e. $\bar{d}=\bar{x}_{e}-\bar{x}_{\mathrm{e}}$. Where $\overline{\mathrm{x}}_{\mathrm{e}}$ is the mean of the experimental test and $\bar{x}_{c}$ the mean of the control test. If $\bar{d}>0$, then there is an improvement and otherwise. The parameter $t$ is calculated by the formula;

$$
\mathrm{t}=\frac{\overline{\mathrm{d}}}{\sqrt{\mathrm{s}^{2} / \mathrm{r}}} \text {, whereby } \mathrm{s}^{2} \text { is sample variance and } \mathrm{n} \text { is the sample size. }
$$

In this study, the paired sample t-used to explore if there is any significant difference in the mean score for the same examination in two different languages. Thus, the standard seven social subjects in the English examination were the experimental group and that in Kiswahili language was the control group.

\subsection{Testing the Paired Sample t-test Assumptions}

The paired sample t-test assumptions were tested before analysis of the suitability of the parametric test. The results revealed that data met the criteria for the t-test as follows:-

i. Only data from the same sample can be used. In this study, each student tested twice. First with English examination and letter with Swahili examination.

ii. The dependent variable should be in interval or ratio. In this study, the dependent variable was the student scores, which is a continuous variable.

iii. The variable score difference must be normally distributed. In this study, a box plot in figure 1 indicates that normality assumptions are met. The plot box is asymmetric (non-skewed) with mean and median at the middle implying that the dependent variable was normally distributed. Also, normality is shown in the histogram (figure 2).

iv. There must be no significant outliers in the variable score difference. This assumption tested by the box plot in figure 1 and the assumption met.

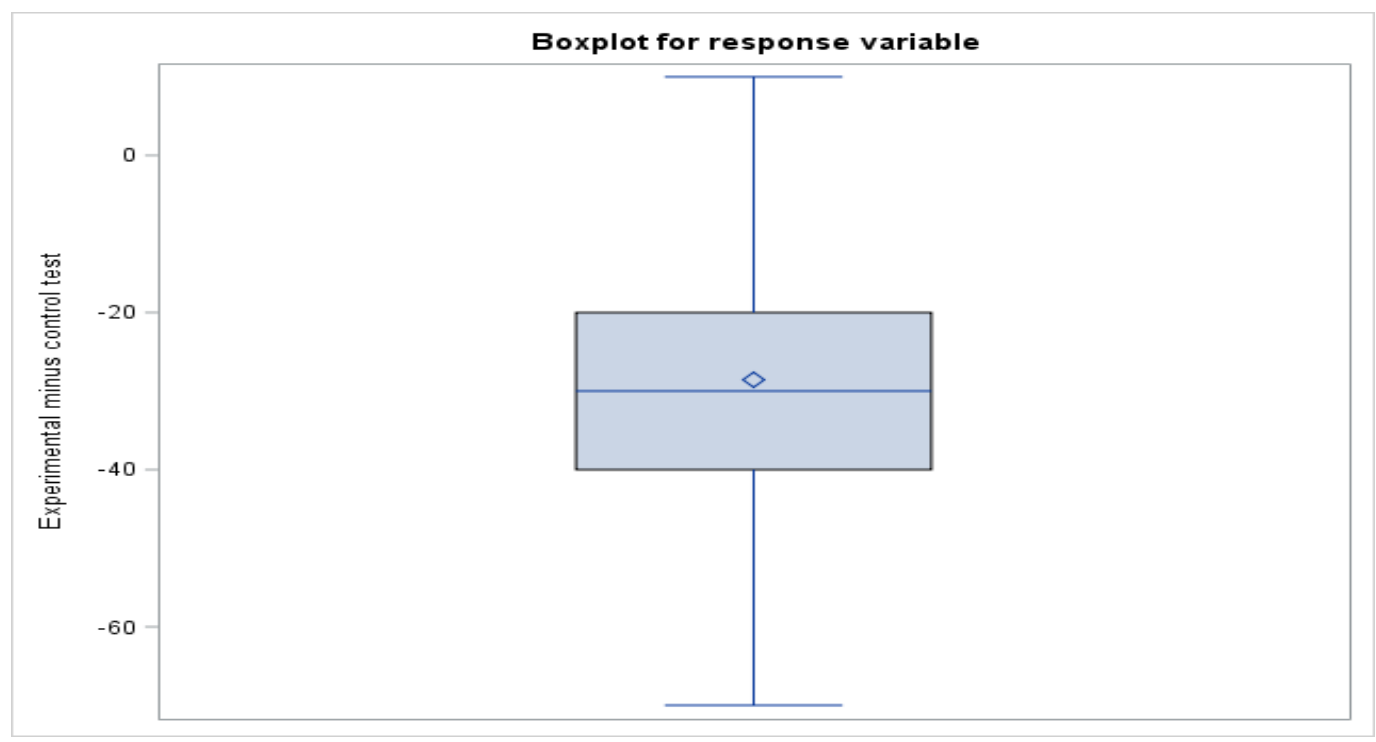

Figure 1. Box plot for students score difference 


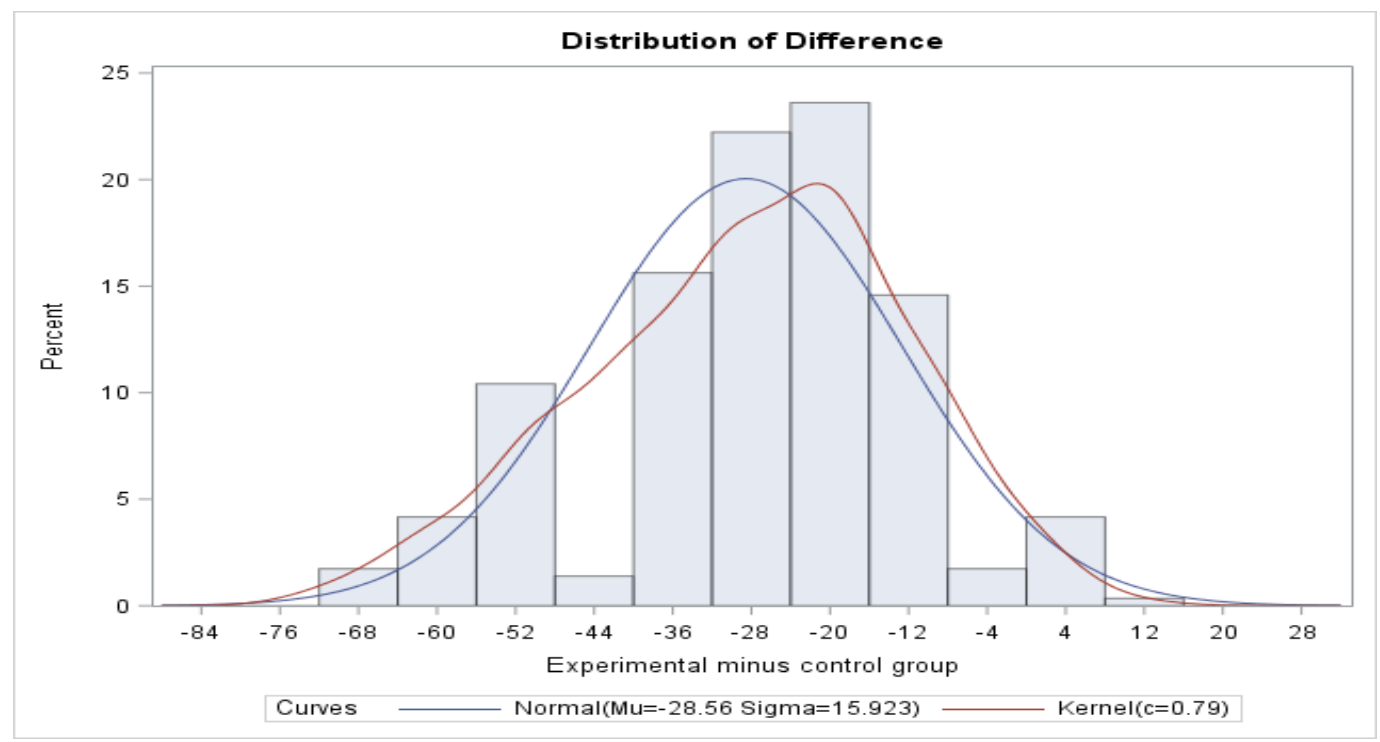

Figure 2. Histogram of students' scores difference.

Source: Survey Data, 2019

\section{Results}

The results on the form one students' academic performance using previous standard seven social subjects examination administered in English and Kiswahili for the same group. The focus was to ascertain whether language is a barrier to the students' understanding of the subjects. The summary of the findings is provided in Table 1.

Table 1. Summary statistics on Minimum and Maximum Students' Scores in Examination

\begin{tabular}{|l|r|l|l|l|r|r|r|}
\hline \multicolumn{7}{|c|}{ Summary statistics } \\
\hline & N & Mean & Std Dev & Std Error & Median & Minimum & Maximum \\
\hline English & 288 & 7.802083 & 10.75021 & 0.633462 & 0 & 0 & 50 \\
\hline Swahili & 288 & 36.04861 & 16.27479 & 0.959001 & 35 & 0 & 80 \\
\hline
\end{tabular}

Source: Survey Data, 2019

Generally, the findings revealed that the minimum score for both examinations (English and Swahili examinations) was 0. The maximum score for English and Swahili examination was 50 and 80 respectively. The mean score for English and Swahili examination observed to be 7.8020833 and 36.0486111 respectively, a difference of -28.2465278 . The median score for English and Swahili examination was 0 and 35 respectively, a difference of -35 . The findings suggest that language use is a determinant in the academic performance of the secondary school students in the study areas as shown in the differences of the maximum scores for the same subjects in English (50 scores) and Kiswahili (80 scores). 


\section{Macrothink}

Journal of Public Administration and Governance

ISSN 2161-7104

2020, Vol. 10, No. 3

4.1 Students'Academic Performance in Grade for the Subject in English and Kiswahili

The segregation of performance results in grades aimed at comparing students' performance of the subject in Kiswahili and English across the grade. It meant to shed light on the difference in performance when the same subject is administered in these two languages. The summary of the results is provided in Figure 3 and Figure 4 for the examination results of the subject in English and Kiswahili respectively.

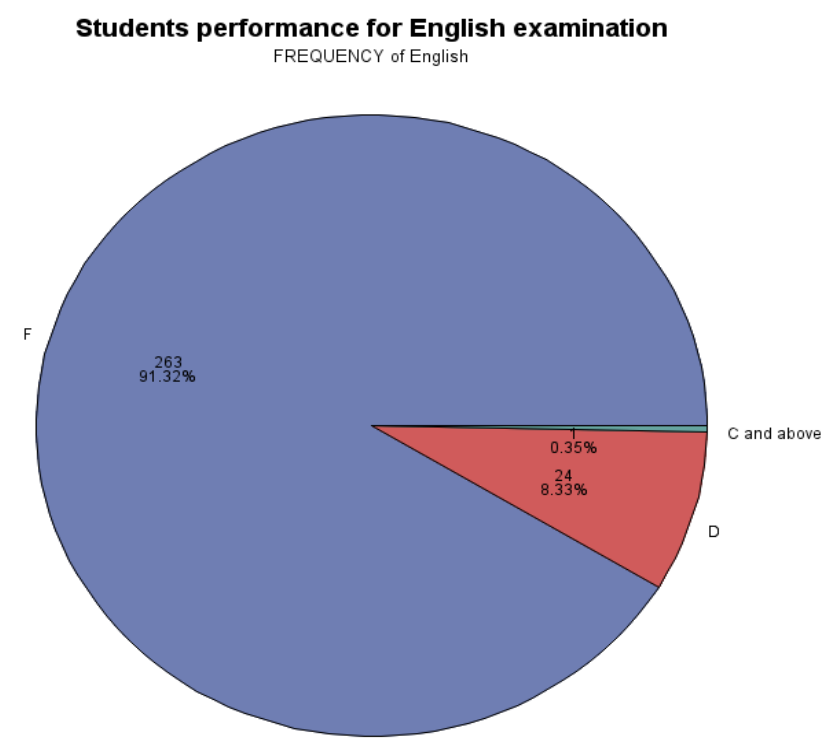

Figure 3. Students performance for English examination

Source: Survey Data, 2019

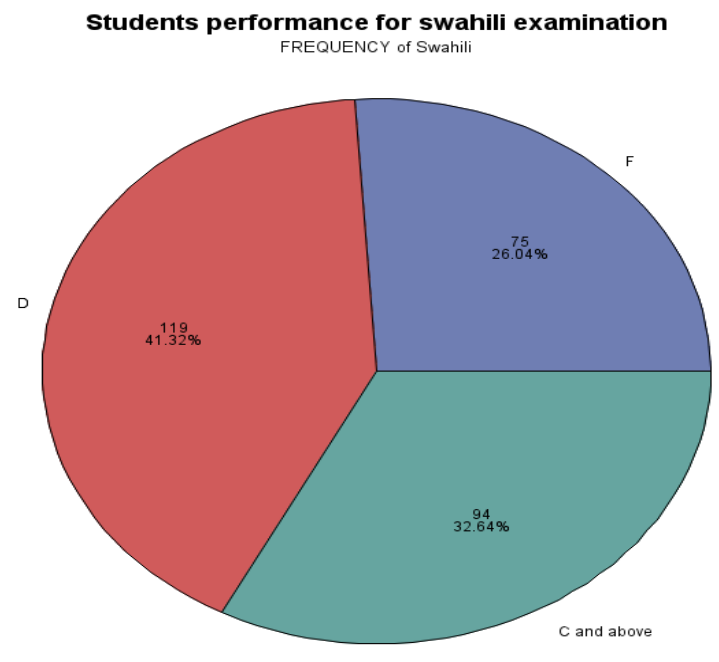

Figure 4. Students performance for Swahili examination

Source: Survey Data, 2019

The students' scores in Figure 3 and Figure 4 are grouped into three groups as follows $\mathrm{F}=$ 
(0-29.44), $\mathrm{D}=(29.5-44.44)$, and $\mathrm{C}$ and above= (44.5 and above). The students' scores in the subject administered in the English language revealed that $263(91.32 \%)$ students scored F, $24(8.33 \%)$ students scored D and only $1(0.35 \%)$ student scored $\mathrm{C}$ and above as shown in figure 3. The results of the same examination administered in Kiswahili revealed that 75 (26.04\%) students scored F, 119 (41.32\%) scored D and 94 (32.64\%) scored C and above for Swahili examination. These results grade-wise imply that the performance appears differing across the grade based on the language of instruction. The improvement in the students' academic performance of the subject administered in Kiswahili is apparent in all grades. The results suggest that students' comprehending subjects are

\subsection{Paired Sample T-Test for Performance Scores of the Subject in English and Kiswahili}

The paired sample t-test on a sample of 288 forms one student at Hombolo and Ipala secondary school was run to determine whether there was a statistically significant mean difference between the score for the examination (social subject) results administered in the English language when compared to the results in the same subject with identical questions administered in Kiswahili language. The results of the paired sample for the results are summarized in Table 2.

Table 2. Paired Sample T-Test for Performance Scores of the Subject in English and Kiswahili

\begin{tabular}{|c|c|c|c|c|c|c|}
\hline Variable & Observations & Mean & $\begin{array}{l}\text { Std. } \\
\text { Error }\end{array}$ & $\begin{array}{l}\text { Std. } \\
\text { Dev. }\end{array}$ & \multirow{3}{*}{\multicolumn{2}{|c|}{$95 \%$ Conf. Interval }} \\
\hline $\begin{array}{c}\text { Performance } \\
\text { Results } \\
\text { (administered in } \\
\text { English) }\end{array}$ & 288 & 7.802083 & 0.633462 & 10.75021 & & \\
\hline $\begin{array}{c}\text { Performance } \\
\text { Results } \\
\text { (administered in } \\
\text { Kiswahili) }\end{array}$ & 288 & 36.04861 & 0.959001 & 16.27479 & & \\
\hline Difference & 288 & -28.2465 & 1.116 & 15.74311 & -30.1404 & -26.3526 \\
\hline & \multicolumn{2}{|c|}{ Ha: mean(diff) $<0$} & \multicolumn{2}{|c|}{ Ha: mean(diff) $!=0$} & \multicolumn{2}{|c|}{ Ha: mean $($ diff $)>0$} \\
\hline$t=-29.36$ & \multicolumn{2}{|c|}{$\operatorname{Pr}(T<t)=0.0000$} & \multicolumn{2}{|c|}{$\operatorname{Pr}(|\mathrm{T}|>|\mathrm{t}|)=0.0000$} & \multicolumn{2}{|c|}{$\operatorname{Pr}(\mathrm{T}>\mathrm{t})=1.0000$} \\
\hline
\end{tabular}

Source: Survey Data, 2019

The analysis in Table 2showed that, the mean score difference (experimental minus control test) was $-28.2465 \pm 16.3293$. That means students' scores for the examination administered in 
English decreased by an average of 28.2465 compared to the same examination administered in the Kiswahili language. That is to say, there was a statistical decrease of 28.2465 marks, with $95 \%$ Confidence Level of $(-30.1404,-26.3526)$. Test statistic $t$ was -29.36 . Thus, the Null hypothesis (mean scores for the subject administered in Kiswahili and English language are equal) is rejected since the p-value was 0.0001. The findings suggest that the students' understanding of training and learning is affected by the type of language used as reflected by their academic performance.

\subsection{Paired Profile for Examination Results in English and Kiswahili}

The paired profile was undertaken to ascertain the effects of the use of Kiswahili and English language in testing the students' academic performance for the social subject. The results helped to illustrate changes in the students' performance when the examination is administered in these languages. Likewise, it determines the size of the effect of using Kiswahili and English language in the understanding of the student as reflected by the examination results. The analysis is shown in Figure 5.

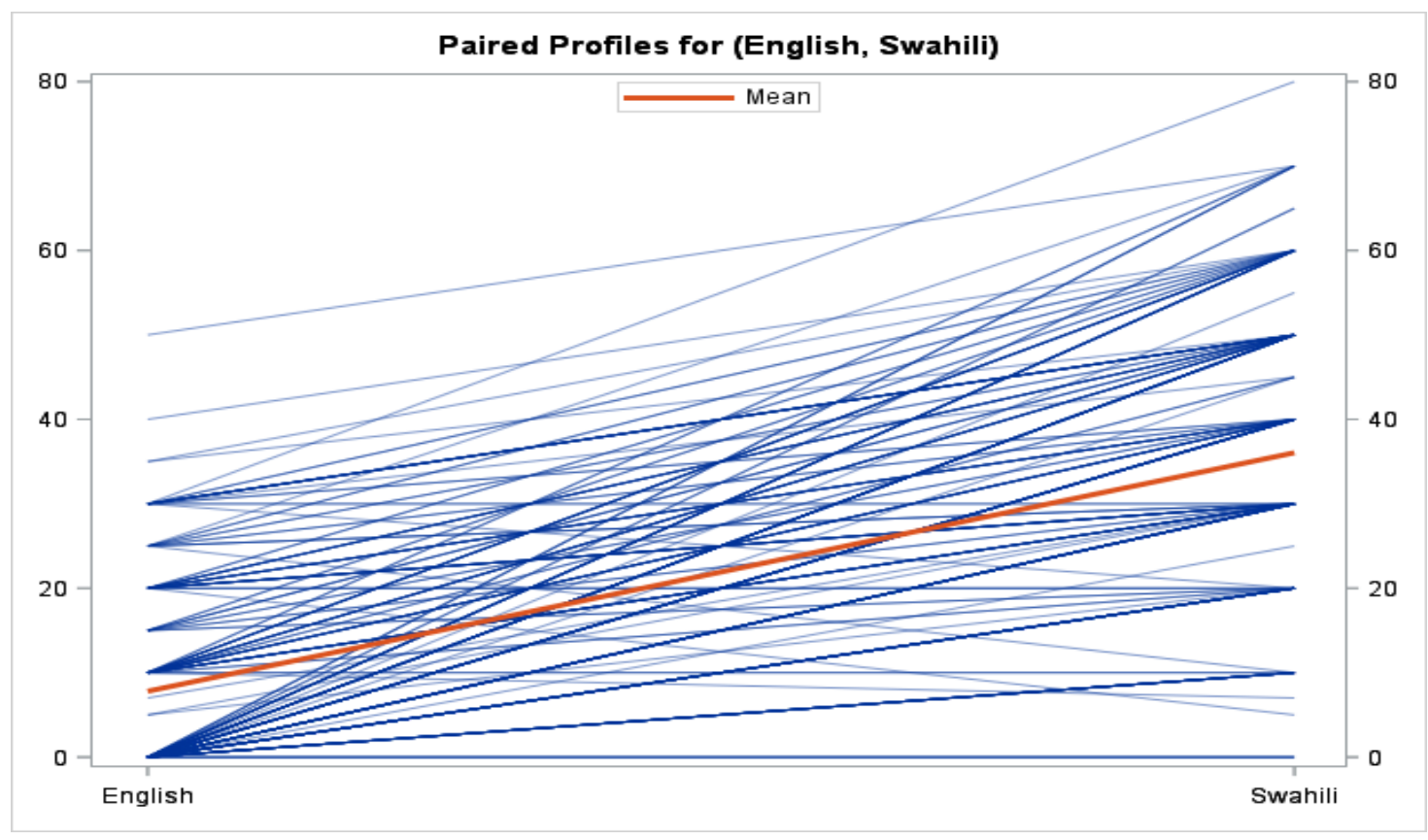

Figure 5. Paired profile for Kiswahili and English

Source: Survey Data, 2019

The paired profile in figure 5, shows that the mean score (red line) increased for examination results administered in Kiswahili when compared to the results of the same examination administered in the English language. Further, the paired sample lines have positive slopes indicating more increase in score for examination in Kiswahili when compared to the same examination in the English language.

Likewise, the findings established the magnitude of the effect of administering the subject in

English and Kiswahili language. It is calculated by Eta squared $=\frac{t^{2}}{t^{2}+(n-1)}$. Whereby " $t$ " is a t-test 
statistic and " $n$ " is the sample size. Substitution gives squared $=\frac{\left([-29.96)^{2}\right.}{(-29.36)^{2}+(289-1)} \approx 075022 \approx 75 \%$.

From the result, it is apparent that the magnitude of the effect is large since the value of Eta squared is extremely large as it is more than 0.5. The values of Eta squared range from zero to one i.e. $0 \leq \mathrm{E} \leq 1$. This provides a further suggestion that the students' academic performance is affected by the conversant with the language of instructions.

\section{Discussion}

Based on the findings it is clear that the students' academic performance is substantially influenced by the use of the language of the learners conversant. In Tanzania, although Kiswahili and English are discerned as official languages, English is seldom used when compared to Kiswahili. Unlike the English language, which is used for training and learning at secondary and tertiary education, the use of Kiswahili goes beyond training and learning; it is a commonly used language in day-to-day life of most of the Tanzanians. This makes most of the students conversant with Kiswahili as compared to the English language. It is by the students being conversant with Kiswahili language that the maximum score for the subject in Swahili is higher (80) when compared to the same subject in English, which stands at 50. Rafiu and Nwalo (2016), Kirui et al. (2017), established similar findings, Rudd, and Honkiss (2020) who documented that infrequent use of the teaching and learning language hindered its mastery and hence affecting training and learning. The use of sudden change from the use of Kiswahili to the English language after more than seven years at primary school and the continued use of Kiswahili in the day-to-day lives of the majority of the Tanzanians affects the fluency in the language and academic performance. To some extent, the findings of this study, relate with the findings by Komba and Bosco (2015) who established that students whose medium of instruction at primary school level was English, performed better inform one annual examination and form two national examinations. Also, the findings of this study correspond to the findings by Prinsloo et al. (2018) who established that frequency with which the learners used the school language at home was strongly associated with academic performance. Thus, the students' academic performance in the study area is affected by a similar challenge. The challenge appears to be more challenging because the mother tongue, a language different from Kiswahili and English is commonly used in their daily life. Further, unlike previous studies, the findings of this study took different root by assessing the students' performance of the same subjects using English and Kiswahili language for the past years standard seven examinations. The differences in scoring for the subject indicate that students face language barriers in learning and presenting the learned knowledge.

The students' poor performance in the examination administered in the English language was different along with the grades. For example, while only $0.35 \%$ of the student scored grade $\mathrm{C}$ in the examination administered in English language $32.64 \%$ of the students scored grade $\mathrm{C}$ and above on the same subject conducted in Kiswahili for the same students. The findings of this study correspond to the findings by Brock-Utne (2007), Marie (2013), McCoy (2017), and Kirui et al. (2017) whose findings identified inadequate proficiency in the language as 
the hindering factor for the students' academic performance. The findings of the study at Ipala and Hombolo secondary school extend further by shading light that not only the total students' scores but also grade-wise, performance of the subject conducted in Kiswahili scores were higher than the same conducted in English. This is evidenced by the paired t-test results that the students' scores for the examination administered in English decreased by an average of 28.2465 when compared to the same examination in Kiswahili language with the effect size of $75 \%$. Hence, this led to rejecting the Null hypothesis that the mean scores for the subject administered in Kiswahili and English language are equal. The findings indicate that students find it difficult to comprehend the knowledge in the language they are neither conversant nor fluent. This is in line with the behaviorism theory whereby teachers and responses by the students (Taylor and MacKenney, 2008 and Fulton and Pritchard, 2009) connect training and learning to stimulus. Nevertheless, the language barrier by both teachers and students make it difficult to set the correct stimulus and for the students to correctly respond to the stimulus. Thus, as supported by Taylor and MacKenney (2008) and Fulton and Pritchard (2009) and Edgar (2012) in such a situation, effective training and learning are impaired. Likewise, the language barrier inhibits the active involvement of the teachers and students, which makes teaching and learning effective for context-specific requirements as, provided for by the constructivism theory impossible (Sjøberg, 2010, Suhendi, and Purwarno, 2018). The inadequate participation in learning not only makes it difficult to accumulate knowledge based on the existing stock of knowledge built on the learners but also it becomes difficult for learners to comprehend the knowledge. Thus, the barrier in language ultimately detrimentally affects the pace with which the young generation is prepared to participate in the social and economic development of the country. With a training approach whose language of training and learning is obscured to both trainers and trainees, acquisition of the prerequisite knowledge becomes difficult. The use of English as an instructional language in secondary schools is contrary to the National Education Policy, 2014 that directs the use of Kiswahili to facilitate the preparation of the workforce with prerequisite knowledge and skills to speed up the realization of the National Development Vision 2025 (UTR, 2014).

\section{Conclusion}

Language is an important vessel for training and learning. Effective training and learning depend on being conversant and fluent in the used language. We found that students' performance in the social subject at Ipala and Hombolo secondary school was substantially affected by language barriers. Students depicted high scores of the examination administered in Kiswahili, the language commonly used by the majority of the citizens in day-to-day life when compared to the results of the same subject conducted in the English language. Specifically, it was revealed that mean students' scores for the examination administered in English decreased by an average of 28.2465 as indicated by the paired t-test with an effect size of $75 \%$. Since we used standard seven past papers to test form one students' academic performance for one subject in English and Kiswahili language, the findings imply that students face difficulties in understanding and demonstrating in writing. It was also found that using English in teaching and learning detrimentally affects the interaction between the trainers and trainees, which is important for effective training and learning. Thus, the 
continued use of the English language in teaching secondary education is negatively affecting acquisition of knowledge, which sets the base for skill acquisition at higher training institutions and preparation of the young generation to productively participate in the social and economic development of the country. We are aware that in June 2020, the World Bank declared that Tanzania has graduated from low income to middle economy. Sustaining the notable achievement and triggering further development, preparation of effective workforce for the purpose is a paramount factor for success. Nevertheless, the continued use of English in secondary education, a language that students cannot understand is a thorn to the future workforce preparation. This in turn is likely to impair the speed with which to accelerate the development in the country. We therefore recommend to design operational strategies for implementation of the National Education and Training Policy, 2014 that directs the use of Kiswahili as the instructional language in primary, secondary and tertiary education in the country. The effective implementations of the policy will address the challenges in training and learning. Further, there are also other important aspects of training and learning, which can contribute to a quality workforce but not covered in this study. The areas include the contents of the syllabus, modes of delivery, and student environments and their impacts on training and learning. We, thus recommend these areas for further studies.

\section{Acknowledgment}

This study was made possible through the efforts and contributions of different people and institutions. Their efforts, contributions, and guidance made this paper successful. We thus express our thanks to the Municipal Director of the City Council of Dodoma for granting permission to undertake the study. We also acknowledge the support rendered by the Local Government Training Institute in communicating with the Municipal Director Research permission. We further acknowledge the assistance made by the Head Master and other teachers at Ipala and Hombolo secondary schools during data collection. Lastly, we appreciate the readiness indicated by the students participating in the research.

\section{Reference}

Addow, A. M., Abubakar, A. H., \& Abukar, M. S. (2013). English language proficiency and academic achievement for undergraduate students in Somalia. Educational Research International, 2(2), 59-66.

Brock-Utne, B. (2007). Learning through a familiar language versus learning through a foreign language - A look into some secondary school classrooms in Tanzania. International Journal of Educational Development, 27(5), 487-498.

Edgar, D. W. (2012). Learning theories and historical events affecting instructional design in education: Recitation literacy toward extraction literacy practices. Sage Open, 2(4), 2158244012462707.

Kinyaduka, B. D., \& Kiwara, J. F. (2013). Language of instruction and its impact on quality of education in secondary schools: Experiences from Morogoro Region, Tanzania. Journal of Education and Practice, 4(9), 90-95. 


\section{$\triangle$ Macrothink}

Journal of Public Administration and Governance ISSN 2161-7104

EJ, K. K. E., Ahmed, O., \& Lyimo, N. (2017). Attitude of teachers towards use of English language as a medium of instruction in secondary schools in Republic of Tanzania: A pragmatic perspective of Community Secondary Schools in Arusha District. Advances in Social Sciences Research Journal, 4(9).

Aina, J. K., \& Olanipekun, S. S. (2013). Effect of English language on academic performance in Physics and Computer Science among College of Education students. American International Journal of Research in Humanities, Arts and Social Sciences, 4(2), 114-117.

Komba, S. C., \& Bosco, S. (2015). Do students' backgrounds in the language of instruction influence secondary school academic performance?

Kagwesage, A. M. (2013). Coping with English as Language of Instruction in Higher Education in Rwanda. International Journal of Higher Education, 2(2), 1-12.

McCoy, B. (2017). Education in an Unfamiliar Language: Impact of Teachers' Limited Language Proficiency on Pedagogy, a Situational Analysis of Upper Primary Schools in Kenya. Journal of Pan African Studies, 10(7), 178-97.

Prinsloo, C. H., Rogers, S. C., \& Harvey, J. C. (2018). The impact of language factors on learner achievement in Science. South African Journal of Education, 38(1).

Rafiu, J., \& Nwalo, K. I. N. (2016). Effect of English Language proficiency on students performance in cataloguing and classification courses in polytechnic-based library schools in Nigeria. International Journal of Library and Information Science, 8(6), 54-61.

Rudd, M., \& Honkiss, L. (2020). Analysing the Correlation between English Proficiency and Academic Performance among Thai University Students. Athens Journal of Education, 7(1), 123-137.

Cekiso, M., Tshotsho, B., \& Masha, R. (2015). English language proficiency as a predictor of academic achievement among primary English first additional language learners in South Africa. International Journal of Educational Sciences, 9(3), 325-333.

Sjøberg S (2010), Constructivism and Learning in Penelope Peterson, Eva Baker, Barry McGraw, (Editors). International Encyclopedia of Education, 5, 485-490. Oxford: Elsevier

Suhendi, A. (2018). Constructivist learning theory: The contribution to foreign language learning and teaching. KnE Social Sciences, 87-95.

URT (2002). The Tanzania Development Vision 2025, Planning Commission of Tanzania.

URT (2014). The National Education and Training Policy, 2014, Ministry of Education.

\section{Copyright Disclaimer}

Copyright for this article is retained by the author(s), with first publication rights granted to the journal.

This is an open-access article distributed under the terms and conditions of the Creative Commons Attribution license (http://creativecommons.org/licenses/by/4.0/). 